\title{
Ad hoc Review of the IUGS Commission on Geoscience for Environmental Management (GEM)
}

Date and Venue of the Review:

2 October 2010 Namibian Geological Survey Building, Windhoek, Namibia.

Ad hoc Review Committee Members:

Colin Simpson - IUGS Councillor (ARC Chair)

Peter Bobrowsky - IUGS Secretary General (ARC Secretary)

Gabi Schneider - Director (Namibian Geological Survey)

Geoff Grantham - Geologist (South Africa Council for Geoscience)

\section{GEM Member Participants:}

Kevin Telmer; Qingcheng He; Jonas Satkunas; Daniel Stapper; Ben Mapani; Sulemana Al-Hassan; Mihir Deb; Monica Jaramillo; Philipp Schmidt-Thome; Igor Zekster; Hisashi Nirei

\section{Rationale for the Review}

In the early 1990s the IUGS Commission for Geosciences and Environmental Planning (COGEOENVIRONMENT) was formed under the umbrella of the International Union of Geological Sciences to address geological issues of an environmental nature. After a successful period of operation, this Commission was formally closed on the occasion of the 2004 IGC in Florence, Italy. At the same congress, a new Commission entitled Geoscience for Environmental Management (GEM) modelled on the previous COGEOENVIRONMENT Commission was pro- posed, approved and ratified by Council. With a revised mandate and different Terms of Reference, a new team of Officers for GEMS was appointed for the timeframe 2004-2008. Subsequently during the 2008 IGC in Oslo, Norway another team of new officers was elected and endorsed by the IUGS-EC and ratified by Council for the period 20082012.

As specified in the Statutes and Byelaws of the Union, the IUGS EC is required to undertake a formal review all Commissions and other bodies funded by the Union on an approximate 4-year cycle. These reports provide accountability for the expenditures incurred by the Union. Consequently, during the Annual Meeting of the IUGS Executive Committee in January 2010 a decision was made that the GEM Commission should be reviewed within the next year. As a result a Review Committee was established comprising two EC members: C. Simpson (as Chair) and P. Bobrowsky (as Secretary), plus two external reviewers: G. Schneider and G. Grantham. The GEM Commission officers were duly notified of the forthcoming review requirement and they were provided with all relevant documentation regarding the review process (e.g. ARC guidelines, and so) prior to the review itself.

The ARC Chair compiled as much background information as possible regarding the past activities of the GEM Commission including copies of recent annual reports for the period 2004-2008, the 4-year report
(2004-2007), and further referred the ARC members to the GEM website at http:// www.iugs-gem.org/. This material proved useful in the evaluation process.

\section{Information to be considered}

At the start of the review process in Windhoek, the ARC Chair Colin Simpson outlined the Terms of Reference (TOR) of IUGS Ad-Hoc Review Committees (previously sent to the GEM Commission). The ARC Secretary Peter Bobrowsky then presented information as background for the review, the requirements for routine IUGS reviews of Commissions as per the Statutes and Byelaws, the types of issues normally addressed during reviews, and the overall process that would be followed during the GEM review to all participants. He specifically outlined the "Report of IUGS Commission 8 on IUGS Rules for Commissions, Task Groups, and Projects" to all those in attendance.

\section{Summary of the interviews with GEM Review participants}

The ARC addressed a range of items, topics and issues relevant to all Commissions in general, but also focussed on particular items important to the GEM Commission:

- progress relative to the original planned activities over the past 4 years;

- mandate and structure delivery and evolution in both; 
- events, products and activities in the Commission during the past 6 years;

- problems, constraints and barriers encountered by the Commission;

- financial situation and history of the Commission;

- GEM Working groups and their progress during the past 6 years;

- relationships with the IUGS and other international bodies; and

- their proposed future and history after 2012.

The GEM participants supplemented their replies primarily by reference to relevant items from their website.

The primary mechanism for the GEM Commission to address science occurs through seven (7) focussed Working Groups:

1. Forensic Geology

2. Gold and Mercury

3. Dust

4. Man-made Strata and Geo-pollution

5. Communicating Environmental Geoscience

6. Climate Change Adaptation

7. Land Subsidence and Groundwater All of the GEM activities listed here have proven to be very relevant, timely, and are attracting global attention, interest and participation.

One significant milestone of the Commission is their new website. Recently updated and restructured their site now provides a site documenting the Commission meetings, courses, events, publications and other activities related to their Working Groups and therefore provides a good historical archive of the Commission achievements. An innovative modification to the website is the ability for members to communicate interactively and in real time via a member secured channel on the web. Materials are easily added, modified and immediately uploaded to the site through this interactive capability.

During the first 4 year term of the Commission, three Working Groups: Geology and Ecosystems, International Cross-Border Geology and Urban Geology successfully reached their objectives and closed. The GEM website clearly summarizes the many activities and outputs (meetings, courses and publications) of these 3 previous Working Groups.

At the moment active members in the Commission comprise 20 individuals from 12 Nations as well as an additional 70 Corresponding Members representing from 43 countries, which is recognized as a reduction in the number of such members supported by the predecessor COGEOENVIRONMENT (see issues). The turn over of officers, $\sim 50 \%$ in the last 4 years is both positive (fresh ideas) and negative (loss of corporate knowledge). In the past year the GEM Commission website received 1,237 visits came from 69 countries/territories.

Since 2009 the Commission has modified the structure of the annual general meetings by reducing the time spent on administrative meeting issues (from 2 to $1 / 2$ day) and added the delivery of locally relevant workshops based on the Working Groups. This innovative shift in philosophy provides a number of positive stimuli: encouraging greater participation by Commission members in the AGM, stimulating growth and attention to the aims of the working groups, enhancing the visibility of the earth sciences to those outside of the discipline, and promotion of the Union.

The Commission plays a major role in a global United Nations Environment Program (UNEP) treaty dealing with small scale mining and the problems of mercury. In this regard GEM has given the IUGS visibility and credibility to a new suite of clients within the UN system. The Working Group on Forensic Geology (the application of geological knowledge in assisting forensic investigations) is strongly focussed on law enforcement entities and has already developed a significant international network of clients to include groups outside of the traditional geosciences.

\section{Issues}

Challenges shared by GEM and other IUGS Commissions are their ability to attract additional people, acquiring general assistance, and obtaining financial support from the outside. In particular, the Commission has had problems keeping a stable Secretary General position and as a result this impacted on their ability to adequately communicate with the IUGS EC and others during the past 1.5 years; a problem which remains unresolved. Similarly, the Commission temporarily addressed the lack of an Information Coordinator, allowing them to modify and update their website, but given that the vacancy remains unresolved, this remains a critical concern relative to the long term sustainability of the site and the functions of the Commission.

Funding for international activities is a problem given that such activities are expensive, but GEM has managed to find a few sponsors. In short, the Commission has managed to leverage about $90 \%$ of their operating funds from the outside ( 10\% of the annual budget comes directly from IUGS). A lack of travel money means that it is difficult to get people in various countries involved in GEM activities. At a minimum the Commission requests sufficient funds to bring all GEM officers to the annual general meeting.

The Commission officers acknowledged that their greatest weakness is in the communications area. Though they have developed an excellent communications platform, the Commission's significant turnover in members has resulted in a need for a communications strategy and a Communications Officer. They would welcome IUGS EC suggestions as to how the Commission can fill such a new position, and how to better advertise/promote the Commission.

The reduction in Corresponding Members during the past decade, and the lack of a strategic plan to recruit new members, suggests the products and outputs of the Commission are reaching a smaller group of individuals, and the reduced number of Members would also limit the potential for finding new Members to volunteer to undertake active roles in GEM positions.

The ARC notes that in 2009 the Commission helped launch a new activity in Forensic Geology. This sub-discipline of research involves the cooperation of geoscientists with non-geoscientists (primarily law enforcement and forensic officers). It has already established a growing international network which is now receiving requests from various police groups for assistance, or the contact information of experts. Like the previous rise of Medical Geology in the Commission and IUGS, the ARC recognizes that this new multidisciplinary effort provides many exciting opportunities to expand the relevance of geosciences by increasing the number of stakeholders by IUGS promotion of this developing sub-discipline through its worldwide network.

\section{Ad hoc Review Committee On-Site Comments}

During the Review the ARC Members made comments/suggestions aimed at improving GEM activities. These included:

- shift current reliance on new web technology which inhibits Commission visibility, while improving internal 
communications. Unless individuals are already interested in GEM they would not otherwise access the site and those with limited access to the internet (e.g. many in Africa) have no way to stay abreast, as such, regular effective external communiqués are still very much required.

- need to clearly identify the advantages of membership in their Commission and distribute this fact sheet extensively as part of a recruitment strategy.

- consider applying for ICSU grants to obtain additional funds.

- consider reducing the total number of Working Groups (see Recommendations) to allow available funding to be more effective.

- expand the network of collaboration for all Working Groups (at the moment a few Working Groups excel in this effort).

\section{Conclusions and Recommendations}

Since its formal reactivation in 2004 the GEM Commission has made significant advances in their efforts to address key geoenvironmental issues of global relevance on behalf of the IUGS. The ARC recognizes and commends several noteworthy achievements by all members of the Commission including, but not restricted to, the following: sharpening the focus of individual Working Groups; outstanding performance by a number of Working Groups; developing and utilizing web based internal communication platforms; creativity in accessing external funding support; and above average attention in the use of Episodes for publication. (The activities ands achievements of the Commission and its Working Groups are outlined on the IUGS-GEM website)

Based on this review the ARC Committee recommends the following:

1. The Commission should resolve their interim solutions regarding vacancies in the positions of Secretary General and Information Officer as quickly as possible.

2. The Commission needs to develop and implement effective strategies for both Corresponding Membership recruitment, and for Commission communications.

3. The Commission must demonstrably improve the regularity and effectiveness of communication with the IUGS EC.

4. The GEM ARC recommends the IUGS EC continue to support the Commission until next IGC in 2012.

5. The GEM ARC recommends conditional extension of the Commission for one extraordinary additional term of 4 years in 2012 following satisfactory resolution of points 1, 2 and 3 before the end of 2011 .

6. The Working Group on Forensic Geology warrants immediate elevation to IUGS Initiative status to assist with the development and promotion of this technology.

The ARC members acknowledge the exceptional productivity, and Union support provided by the GEM Commission for the past several years. The ARC members appre-ciate the local and national financial support, logistical assistance and generosity provided by the Government of Namibia via Dr. Gabi Schneider (Geological Survey of Namibia), and Dr Ben Mapani (University of Namibia) in the implementation of this review process.

The IUGS EC members offer special thanks to Dr. Gabi Schneider and Dr Geoff Grantham for their assistance on the Review Committee.

\section{Collin Simpson}

IUGS Councillor

E-mail:simpsons@grapevine.com.au

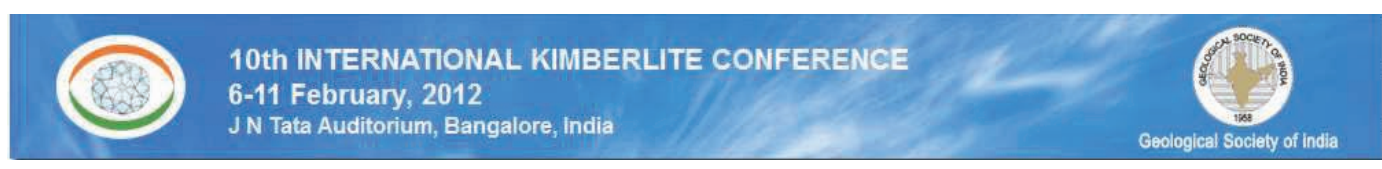

We are pleased to announce the 10th International Kimberlite Conference to be held at Bangalore, India between 6th and 11th February, 2012. The conference is a sequel to the nine successful events at different parts of the world where academic and exploration communities meet to discuss the current status of research on the source rocks of diamonds and the newer techniques evolved in their exploration.

\section{Registration}

The organizing committee encourages all the participants to register early and enjoy significant discount on General registration. The rates are as mentioned below.

\begin{tabular}{|l|c|}
\hline Registration Type & $\begin{array}{c}\text { Registration Fee } \\
\text { INR (Indian rupees) }\end{array}$ \\
\hline General & 48000 \\
\hline Late Registration & 60000 \\
\hline Accompanying person & 12000 \\
\hline
\end{tabular}

\section{Contact details}

Conference Secretariat

No.63, 12th Cross

Basappa Layout, Gavipuram

Bangalore - 560019

Karnataka, India.

Telephone: +919886402487

Telefax: +91 08026613352

Email: secretariat@10ikcbangalore.com : fareedromani@hotmail.com

For Online Abstract Submission and Online Registration please visit the Conference Website at www.10ikcbangalore.com 